\title{
HARDENING OF CALCIUM HYDROXIDE AND CALCIUM SILICATE BINDERS DUE TO HYDRATION AND CARBONATION
}

\author{
Ozlem Cizer ${ }^{1}$, Jan Campforts ${ }^{1}$, Koen Van Balen ${ }^{1}$, Jan Elsen ${ }^{2}$ and Dionys Van Gemert ${ }^{1}$ \\ ${ }^{1}$ K.U.Leuven, Department of Civil Engineering, Building Materials and Technology Division, \\ Kasteelpark Arenberg 40, B-3001 Heverlee, Belgium, e-mail: Ozlem.Cizer@bwk.kuleuven.be \\ ${ }^{2}$ K.U.Leuven, Department of Geography and Geology, Physico-chemical Geology Section, \\ Celestijnenlaan 200C, B-3001 Heverlee, Belgium
}

\begin{abstract}
Hardening of calcium hydroxide and calcium silicate binders composed of cement, rice husk ash (RHA) and lime in different compositions were studied with mechanical strength, mercury intrusion porosimetry, thermal analysis and SEM. When cement is partially replaced with RHA and lime, hardening occurs as a result of combined hydration, pozzolanic reaction and carbonation reaction. While hydration of cement contributes to the early strength development of the mortars, carbonation is much more pronounced at later stage with the decrease in the cement content in the mortar and the increase in the porosity of the mortars. RHA-cement mortars indicated a long-term strength development, which is lower than that of the reference cement mortar. This was attributed to the high water demand of the blended mortars due to the porous RHA grains, which resulted in an increase in their porosity. Strength reduction was recorded at the very early stage for RHA-cement-lime mortars containing $10 \%$-wt cement. This has been explained with the insufficient cement content, destructive effect of the calcium carbonate phases on the initially hydrated cement phases and partial carbonation of the initially hydrated phases.
\end{abstract}

Keywords

RHA, cement, lime, hydration, pozzolanic reaction, carbonation.

\section{INTRODUCTION}

Use of pozzolana as a partial replacement with cement in mortar can improve its ultimate strength and modify its microstructure due to the formation of additional calcium silicate hydrate $(\mathrm{C}-\mathrm{S}-\mathrm{H})$ phases through pozzolanic reaction between the pozzolana and calcium

hydroxide formed during the hydration of cement. This leads to a decrease in the content of the calcium hydroxide in comparison to that of the hydrated cement. Therefore, presence of the pozzolana influences the progress of the cement hydration and its compounds. In fact, hydration mechanism becomes much more complicated since cement hydration and pozzolanic reaction follow different reaction processes at different rates. Hydration of cement proceeds much faster than the pozzolanic reaction that becomes usually effective between 3-14 days of hydration, which is after most of the alite in the cement has hydrated [1]. This period depends relatively on the reactivity and specific surface area of the pozzolana [1-2-3]. Hydration of alite and belite has been reported to be accelerated with the presence of pozzolana [1-3-4-5]. This can be explained by the fact that fine pozzolana grains act as a precipitation site for additional C-S-H phases and dissolution of alite and belite is accelerated as a result of the decrease in the $\mathrm{Ca}^{+2}$ ions concentration due to their consumption through 
pozzolanic reaction [3]. Literature concerning the hydration of cement in the presence of additional lime is rather limited. Hydration of tricalcium aluminate has been reported to be slightly retarded in the presence of lime [6]. It has been found that hexagonal hydro-aluminates are formed with the hydration of tricalcium aluminate. In addition, formation of additional C-S-H by pozzolanic reaction has been reported to result in a pore size refinement effect leading to a decrease in the large pores and increase in the fine pores [7-8-9]. Strength increase of the cement mortars blended with pozzolana is, therefore, correlated with the additional C-S-H formation and pore size refinement effect. Carbonation of the cement blended with pozzolana and lime is generally neglected in the literature.

In this study, hardening of cement mortars in the presence of pozzolana and lime has been studied. Rice husk ash (RHA) has been used as a highly reactive artificial pozzolana. Cement was partially replaced with RHA and lime at different ratios. Results are presented for the hardening mechanism, strength development, porosity, and microstructural modification of the blended mortars with respect to the reference cement mortar.

\section{RESEARCH PROGRAMME}

\section{Materials}

RHA and commercial hydrated lime were used as a partial replacement with Portland cement (CEM I $52.5 \mathrm{~N}$ ) in mortars. RHA provided from Tanzania is composed of high contents of silica $(90.86 \%)$ by weight. XRD analysis indicated its amorphous phase due to the broad band between 15-30 $2 \theta^{\circ}$ (Figure 1). It contained certain amounts of cristobalite and tridymite as crystalline silica. This indicated that RHA was obtained by burning at relatively high temperatures $\left(800-1000^{\circ} \mathrm{C}\right)$, which led to the crystallization of the amorphous silica [10]. In order to be used as a pozzolanic material, the ash was ground by means of a laboratory batch ball mill until certain fineness and surface area $\left(13047 \mathrm{~cm}^{2} / \mathrm{g}\right)$ was reached. The ground RHA grains are mostly angular edged grains with varying particle sizes less than $50 \mu \mathrm{m}$ (Figure 1).
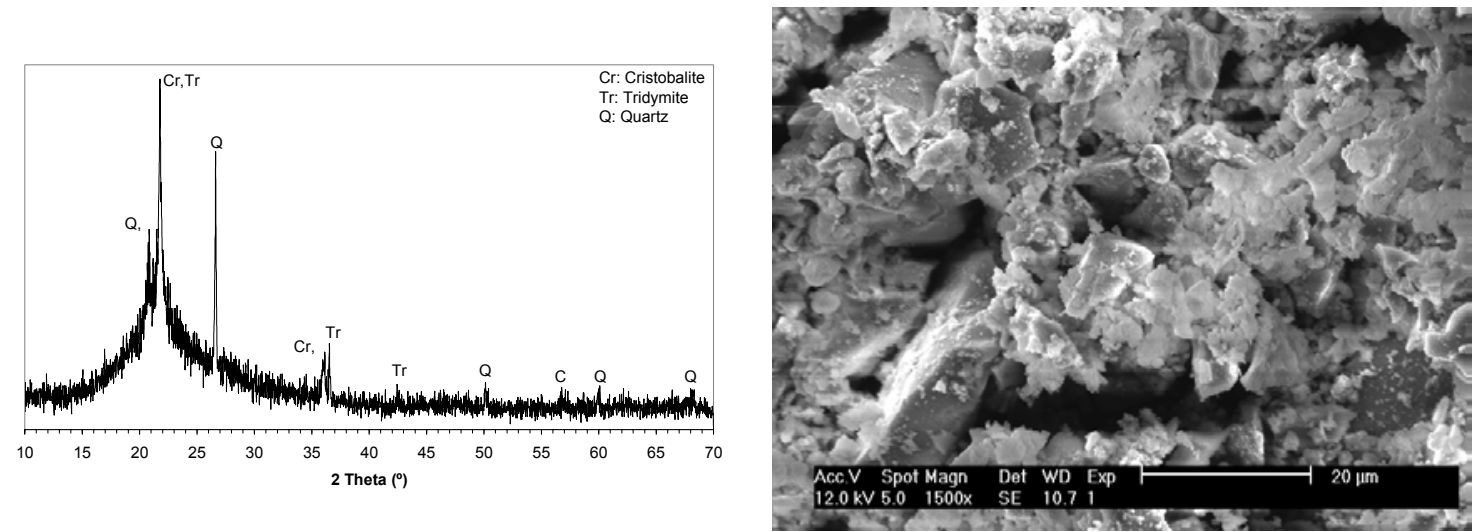

Figure 1. XRD pattern and SEM micrograph of the RHA.

Compositions of the mortars are given in Table 1. The mortars were prepared using standard quartz sand with maximum grain size of $2 \mathrm{~mm}$ [11]. Binder/sand ratio of the mortars was $1: 3$ by weight. Concerning the RHA-cement mortars, cement was replaced at $30 \%$-wt (RHA-C.3-7), 50\%-wt (RHA-C.5-5) and 70\%-wt (RHA-C.7-3) ratio by RHA. Two types of ternary blended mortars composed of RHA, cement and lime were prepared. The ratio of the cement was kept 10\%-wt for both compositions. While one (RHA-C-L.7-1-2) was composed of 70\%-wt RHA and 20\%-wt lime, the other (RHA-C-L.5-1-4) contained 50\%-wt RHA and 
$40 \%$-wt lime. Due to the much more porous structure and higher specific surface area of the RHA and lime particles compared to the cement, they have higher water absorption capacity and water retentivity. This led to the use of more water for the blended mortars to reach similar workability, resulting in different water/binder (W/B) ratios.

Table 1. Compositions of the cement mortars blended with rice husk ash and lime.

\begin{tabular}{|l|l|l|l|l|l|l|}
\hline Mortar & $\begin{array}{l}\text { RHA } \\
(\mathbf{g})\end{array}$ & $\begin{array}{l}\text { Cement } \\
(\mathbf{g})\end{array}$ & $\begin{array}{l}\text { Lime } \\
(\mathbf{g})\end{array}$ & $\begin{array}{l}\text { Sand } \\
(\mathbf{g})\end{array}$ & $\begin{array}{l}\text { W/B } \\
(\mathbf{b y} \text { weight })\end{array}$ & $\begin{array}{l}\text { Flow } \\
(\mathbf{m m})\end{array}$ \\
\hline Cref & - & 450 & - & 1350 & 0.48 & 144 \\
\hline RHA-C.3-7 & 135 & 315 & - & 1350 & 0.60 & 150 \\
\hline RHA-C.5-5 & 225 & 225 & - & 1350 & 0.65 & 146 \\
\hline RHA-C.7-3 & 315 & 135 & - & 1350 & 0.70 & 147 \\
\hline RHA-C-L.7-1-2 & 315 & 45 & 90 & 1350 & 0.80 & 151 \\
\hline RHA-C-L.5-1-4 & 225 & 45 & 180 & 1350 & 0.82 & 148 \\
\hline
\end{tabular}

\section{Methods}

Hardening of the mortars was studied using standard mortar beams $(40 \times 40 \times 160 \mathrm{~mm})$ which were prepared in accordance with the European standards [11]. Mortars were cured at the standard laboratory conditions $\left(20^{\circ} \mathrm{C}, 60 \%\right.$ R.H.) for 180 days. The progress of hardening was studied by means of mechanical strength, porosity, phenolphthalein staining, thermal analysis and Scanning Electron Microscope. Mechanical strength tests were carried out by compressive and three-point bending tests using the standard mortar beams at 7, 28, 60, 90, 120 and 180 days of hardening [11]. Progress of carbonation of the mortars during curing was tested using phenolphthalein solution. Open porosity of the mortars was determined according to water saturation test by hydrostatical weighing [12]. Pore size distribution of the mortars was studied using Mercury Intrusion Porosimetry (Micromeritics AutoPore IV). Thermal analysis was performed on finely ground samples after they were dried by vacuum drying at $0.025 \mathrm{mbar}$. The analysis was carried out using a Netzsch STA 409 PC DSC-TGA system in static nitrogen atmosphere at a temperature range between $20-1000^{\circ} \mathrm{C}$ with a controlled heating rate $10^{\circ} \mathrm{C} / \mathrm{min}$. Microstructure of the fresh fractured surfaces coated with gold was analyzed using Philips XL 30S FG Scanning Electron Microscope (SEM) coupled with $\mathrm{X}$-Ray Energy Dispersive System (EDS).

\section{RESULTS}

\section{Mechanical strength}

Progress of compressive and flexural strength of the reference cement mortar and RHA-cement mortars are given in Figure 2 and Figure 3. While reference cement mortar yielded the highest compressive and flexural strength values at all stages, the values became lower as cement was partially replaced by RHA in 30\%, 50\% and 70\%-wt ratio respectively. All the mortars achieved their ultimate compressive strength at 7 days of hardening and strength development continued until 28 days. After that, the compressive strength of only RHA-C.5-5 and RHA-C.7-3 mortars increased gradually until 180 days of hardening.

RHA-cement mortars yielded an increasing flexural strength development until 180 days (Figure 3). Increase in the flexural strength of the RHA-C.3-7 mortar between 7 and 28 days was more than that of RHA-C.5-5 and RHA-C.7-3 mortars having lower cement content. Strength development of these two mortars between 28 days and 180 days was much more pronounced than that of RHA-C.3-7. 


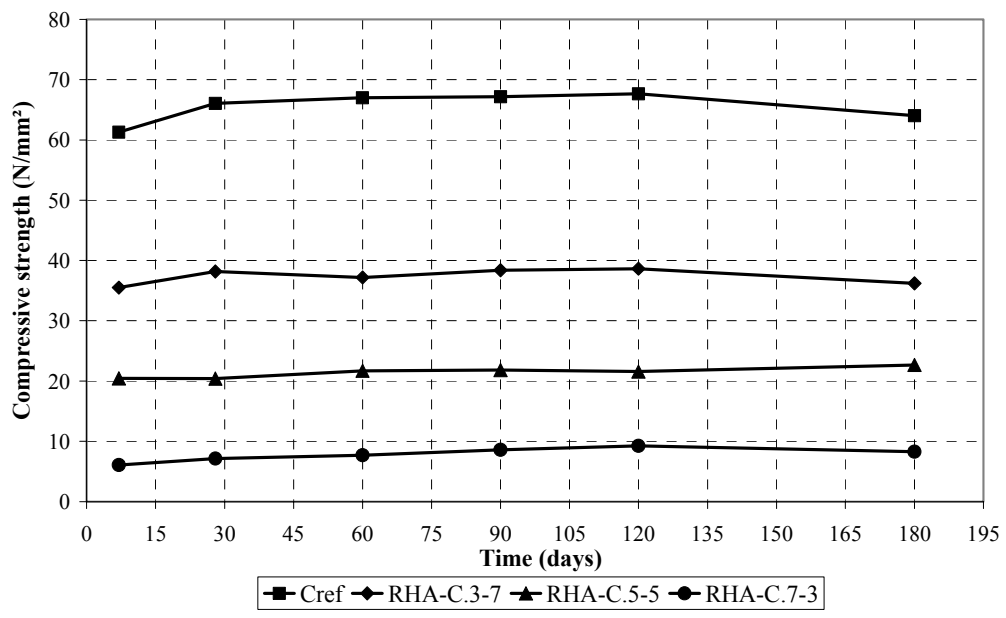

Figure 2. Compressive strength of the reference cement mortar and RHA-cement mortars after $7,28,60,90,120$ and 180 days of hardening.

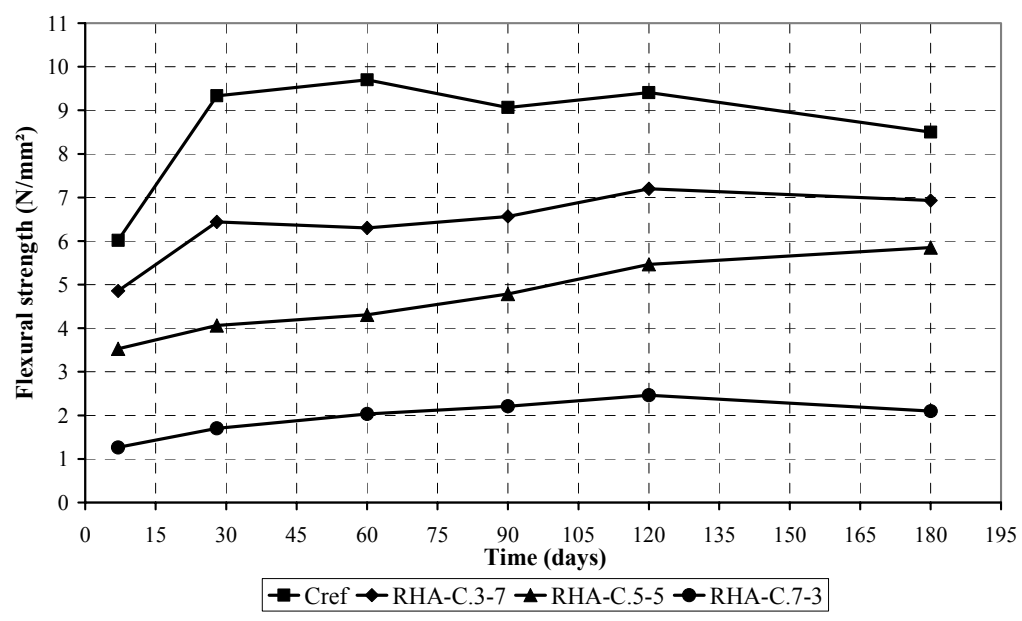

Figure 3. Flexural strength of the reference cement mortar and RHA-cement mortars after $7,28,60,90,120$ and 180 days of hardening.

RHA-cement-lime mortars yielded relatively lower compressive and flexural strength values than those of the RHA-cement mortars. Reduction in compressive and flexural strength was recorded at the very early stage after 28 days of hardening (Figure 4 and Figure 5). Compressive strength of RHA-C-L.5-1-4 mortar did not change that much between 28 and 60 days while it decreased after 60 days. However, its flexural strength decreased between 28 and 60 days but after that it stayed almost at the same value until 120 days followed by a decrease at 180 days. Strength reduction was much more pronounced for RHA-C-L.7-1-2 mortar between 28 and 180 days even though its initial strength was higher than that of the other. Its compressive strength decreased from $6.23 \mathrm{~N} / \mathrm{mm}^{2}$ to $2.67 \mathrm{~N} / \mathrm{mm}^{2}$ and its flexural strength from $0.68 \mathrm{~N} / \mathrm{mm}^{2}$ to $0.32 \mathrm{~N} / \mathrm{mm}^{2}$. 


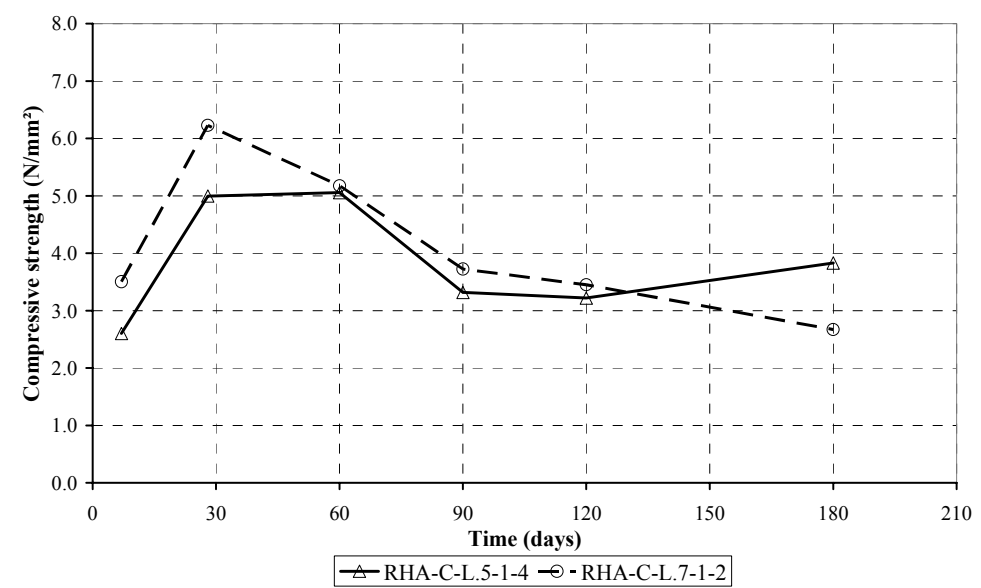

Figure 4. Reduction in the compressive strength of the RHA-C-L.7-1-2 mortar after 28 days and that of RHA-C-L 5-1-4 mortar after 60 days.

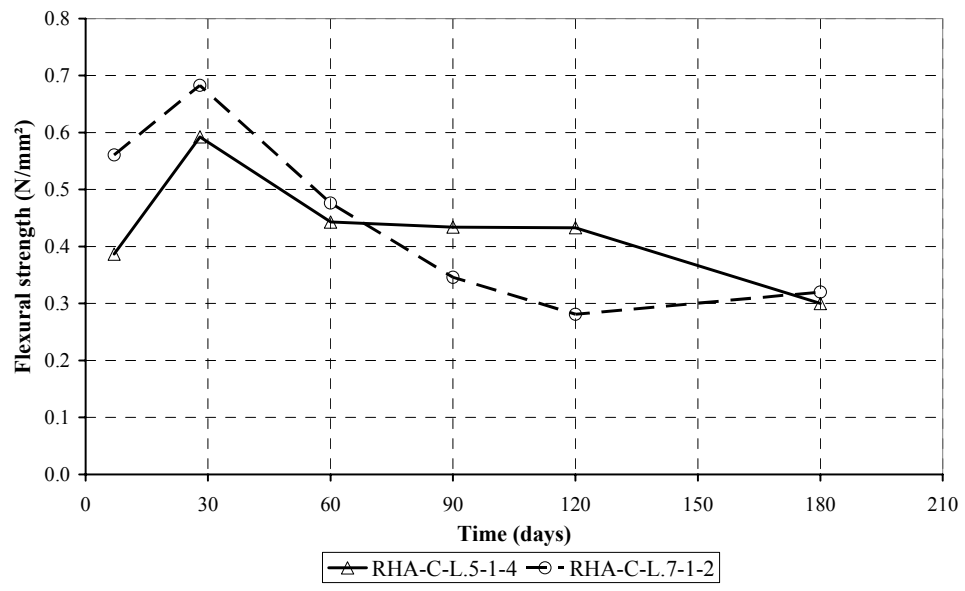

Figure 5. Reduction in the flexural strength of the RHA-cement-lime mortars after 28 days.

\section{Open porosity and pore size distribution}

Open porosity of the mortars determined at 60,90 and 120 days of hardening are given in Table 2. While reference cement mortar had the lowest open porosity, RHA-cement mortars yielded an increase in the open porosity as the RHA content increased, leading to high $\mathrm{W} / \mathrm{B}$ ratio. RHA-C-L.7-1-2 and RHA-C-L.5-1-4 mortars had the highest porosity since they contained $20 \%$ and $40 \%$ lime respectively and only $10 \%$ cement by weight.

Table 2. Open porosity of the mortars at 60, 90 and 120 days of hardening.

\begin{tabular}{|l|c|c|c|}
\hline \multirow{2}{*}{ Mortar } & \multicolumn{3}{|c|}{ Open porosity } \\
\cline { 2 - 4 } & $\mathbf{6 0}$ days & $\mathbf{9 0}$ days & $\mathbf{1 2 0}$ days \\
\hline Cref & $13.6 \%$ & $14.1 \%$ & $12.5 \%$ \\
\hline RHA-C.3-7 & $19.3 \%$ & $19.5 \%$ & $18.4 \%$ \\
\hline RHA-C.5-5 & $21.8 \%$ & $22.2 \%$ & $21.6 \%$ \\
\hline RHA-C.7-3 & $25.9 \%$ & $25.7 \%$ & $25.4 \%$ \\
\hline RHA-C-L.7-1-2 & $30.7 \%$ & $30.8 \%$ & $29.4 \%$ \\
\hline RHA-C-L.5-1-4 & $31.4 \%$ & $31.1 \%$ & $29.7 \%$ \\
\hline
\end{tabular}


Pore size distribution of the mortars was determined at 90 days of hardening (Figure 6). RHA-cement mortars had higher volume of smaller and larger pores when compared with the reference cement mortar. RHA-cement-lime mortars yielded the highest porosity with their higher volume of large and small pores than the rest. This is mostly related to their composition as they contain only $10 \%$-wt cement and high W/B ratio.

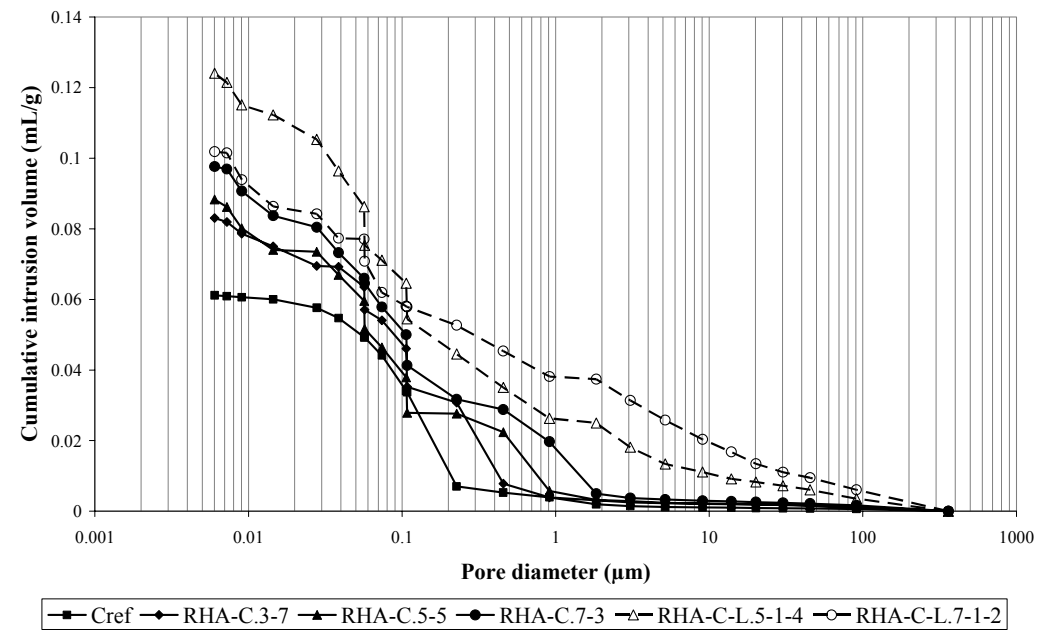

Figure 6. Pore size distribution of the mortars after 90 days.

\section{Carbonation depth}

Carbonation depth of the mortars increased as the content of the cement decreased in the mortar (Figure 7). RHA-C.7-3 containing the lowest cement content (30\%-wt) reached a full carbonation depth at 60 days of hardening while other RHA-cement mortars still contained uncarbonated calcium hydroxide at the core at 180 days. RHA-cement-lime mortars reached a full carbonation depth at 180 days.

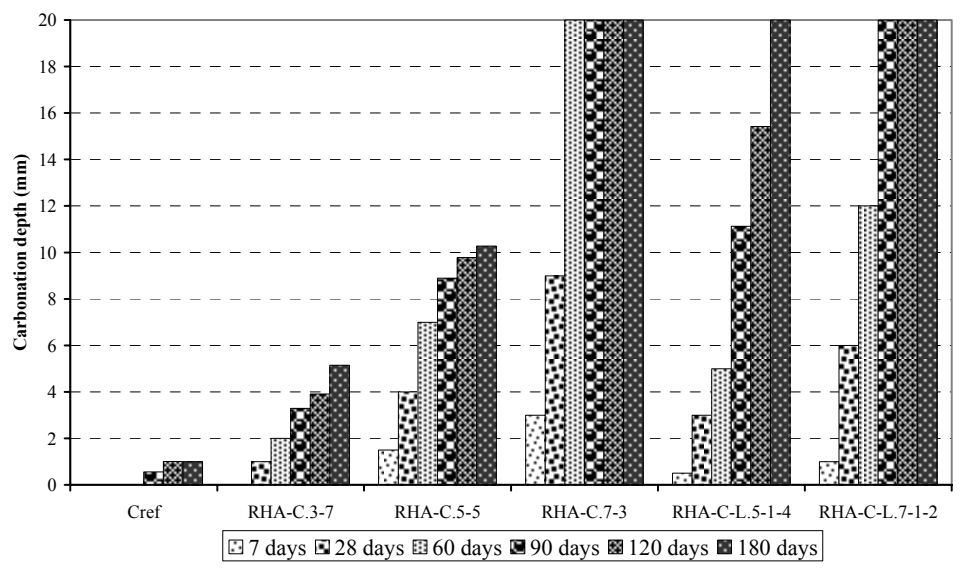

Figure 7. Carbonation depth for the reference and blended cement mortars after $7,28,60,90,120$ and 180 days of hardening.

\section{Thermal analysis (DTG)}

Progress of hardening of the mortars was followed by thermal analysis. Derivative of the weight loss (DTG) of the Cref, RHA-C.3-7 and RHA-C.5-5 mortars are given in Figure 8. Weight loss between $100^{\circ} \mathrm{C}$ and $200^{\circ} \mathrm{C}$ was attributed to the dehydration of hydrated phases and the loss at around $450^{\circ} \mathrm{C}$ was due to the decomposition of calcium hydroxide. Weight loss 
recorded between $500^{\circ} \mathrm{C}$ and $800^{\circ} \mathrm{C}$ was derived from the carbonated phases. Results revealed that partial replacement of cement by RHA led to a decrease in the calcium hydroxide content and an increase in the carbonated phases. Further decrease in the cement content resulted in a decrease in the hydrated phases. In the RHA-cement-lime mortars, carbonated phases were much more pronounced than the hydrated phases.
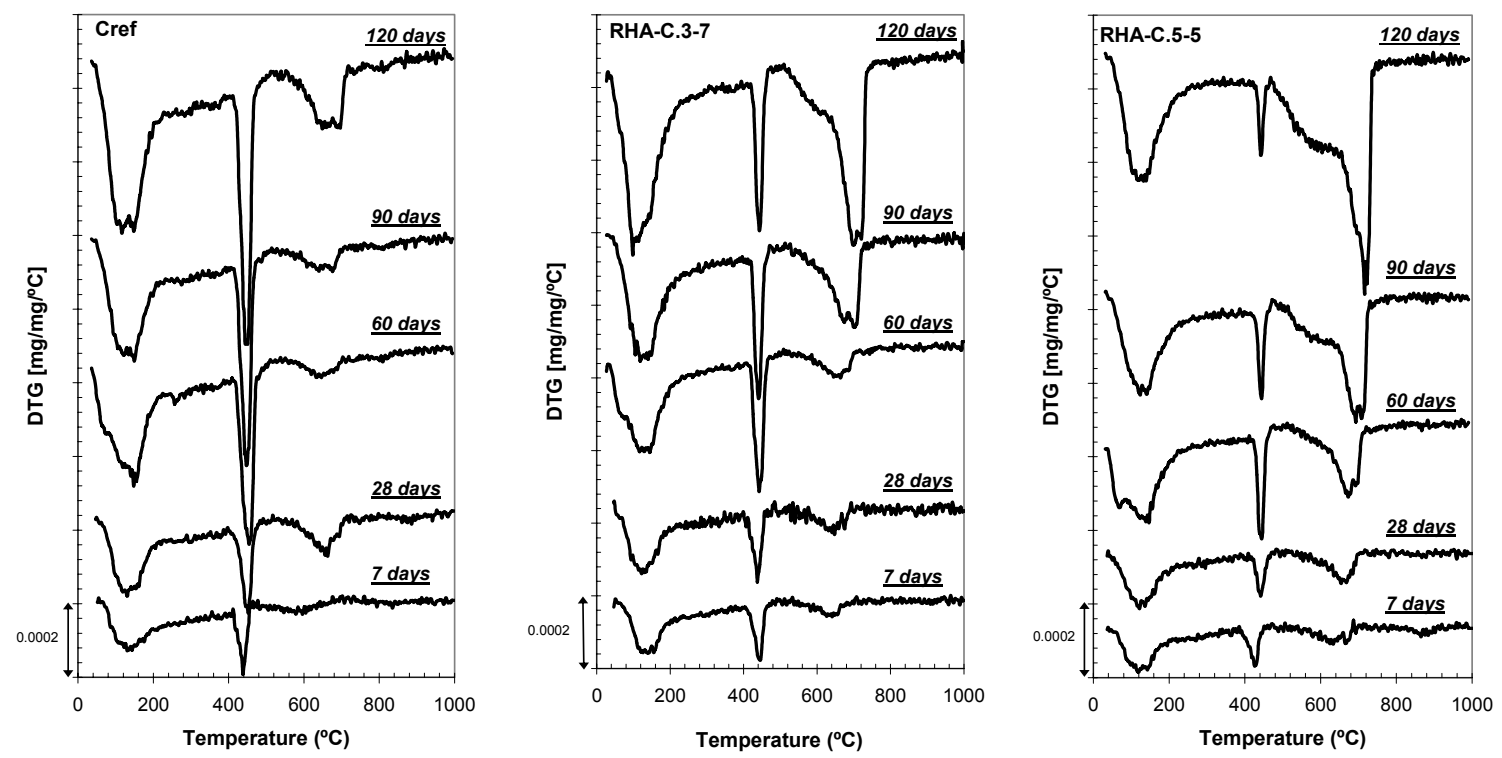

Figure 8. Derivative of the weight loss (DTG) of the Cref, RHA-C.3-7 and RHA-C.5-5 mortars at 7, 28, 60, 90 and 120 days of hardening.

\section{Microstructure of the mortars}

Use of RHA and lime together with cement led to differences in the microstructure of the mortars. Reference cement mortar was characterized by needle-like and reticular C-S-H phases, and calcium hydroxide crystals formed inside the pores and in the matrix (Figure 9). In the RHA-cement mortars, flocs-like and fibrous-like C-S-H phases that were well connected to each other filled the pores of the mortar (Figure 10). Needle-like C-S-H phases were not observed that much in the matrix of these mortars.

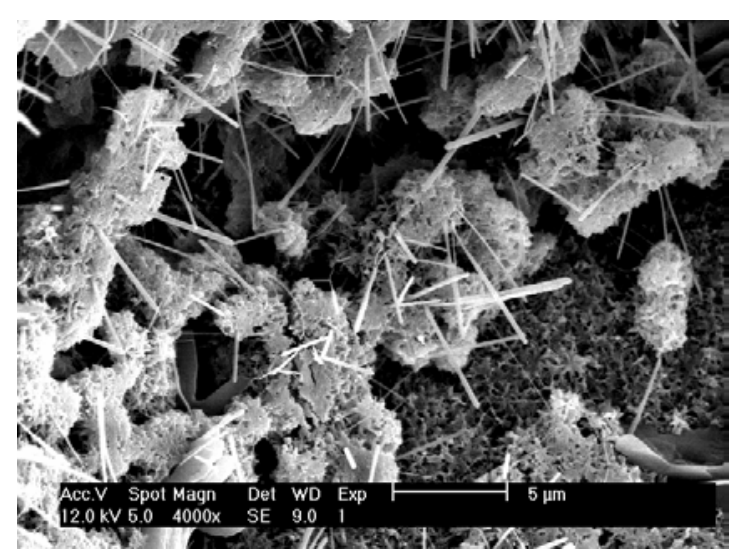

Figure 9. SEM micrographs of needle-like and reticular C-S-H phases formed inside the pore of the Cref after 120 days of hardening.

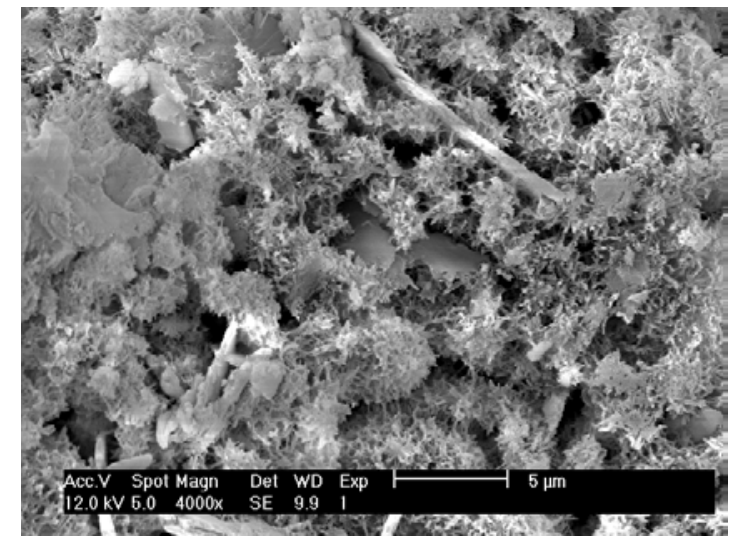

Figure 10. SEM micrographs of flocs-like C-S-H phases formed in the matrix of RHA-C.5-5 after 120 days of hardening. 
Plate-like, semi-circle and round RHA particles, which remained substantially unreacted or partially reacted after 120 days, were embedded within the matrix (Figure 11a-b). These RHA grains acted as a surface for the precipitation of additional C-S-H phases through pozzolanic reaction with calcium hydroxide formed during the cement hydration (Figure 11c). When totally reacted, flocs-like C-S-H phases were formed (Figure 11d). These hydrated phases played a bridging role between hydrated and unhydrated cement compounds by growing from the grain surface towards the surrounding matrix. Cluster of calcium hydroxide crystals embedded in the matrix were still detectable in the RHA-cement mortars after 120 days.
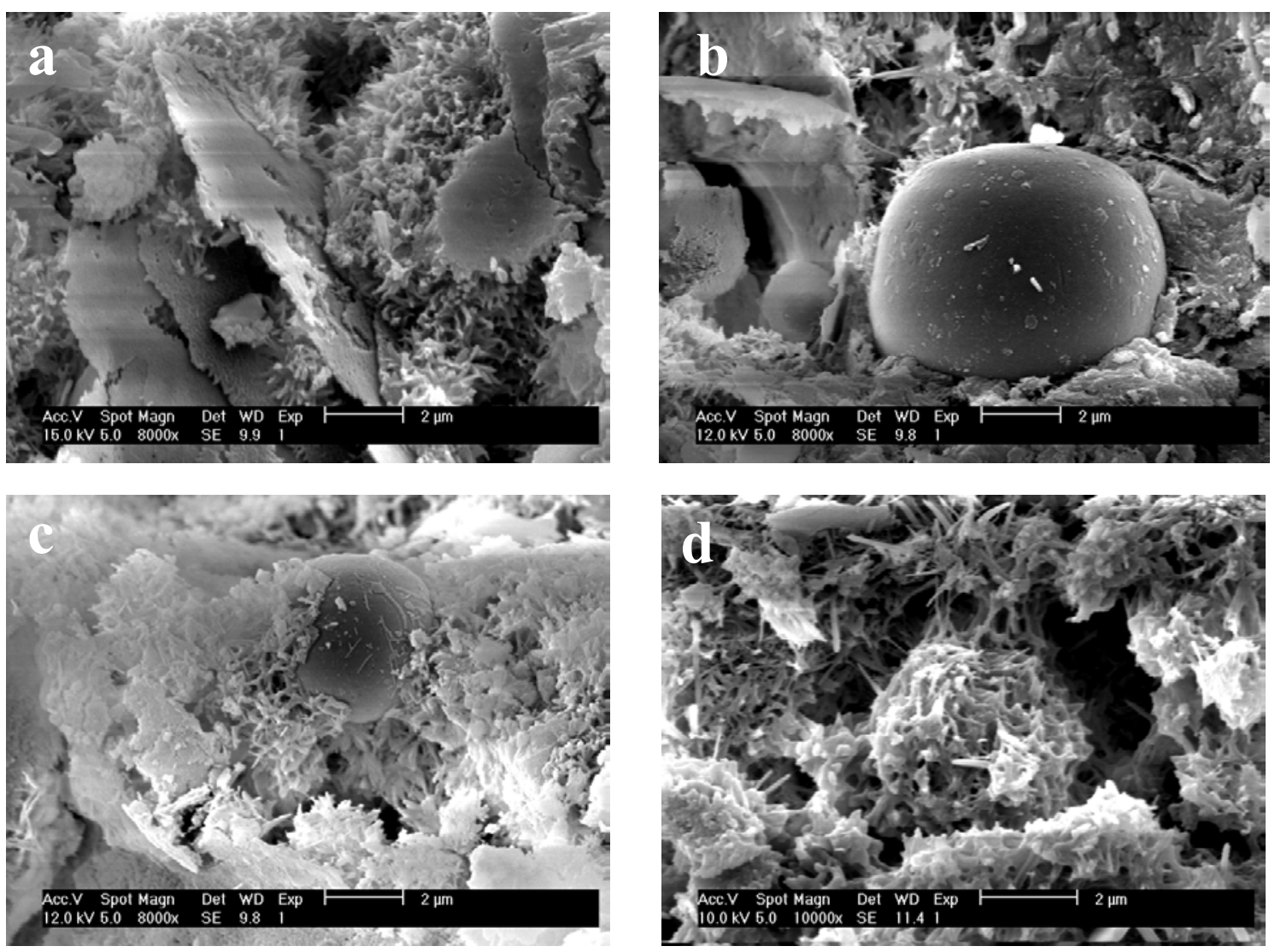

Figure 11. SEM micrographs of the matrix of RHA-C.5-5 mortar after 120 days of hardening, showing unreacted RHA grains (a-b), C-S-H phases started to form on the surface of a RHA grain (c), RHA grain that has reacted, forming amorphous C-S-H (d).

RHA-cement-lime mortars exhibited a totally different microstructure when compared with the RHA-cement mortars (Figure 12). The matrix was rich in silica and carbonated phases and was composed of agglomerated dense phases with rather large pores in-between. Clusters of needle-like crystals and hexagonal plate-like crystals embedded locally within the carbonated matrix were observed (Figure 12). 

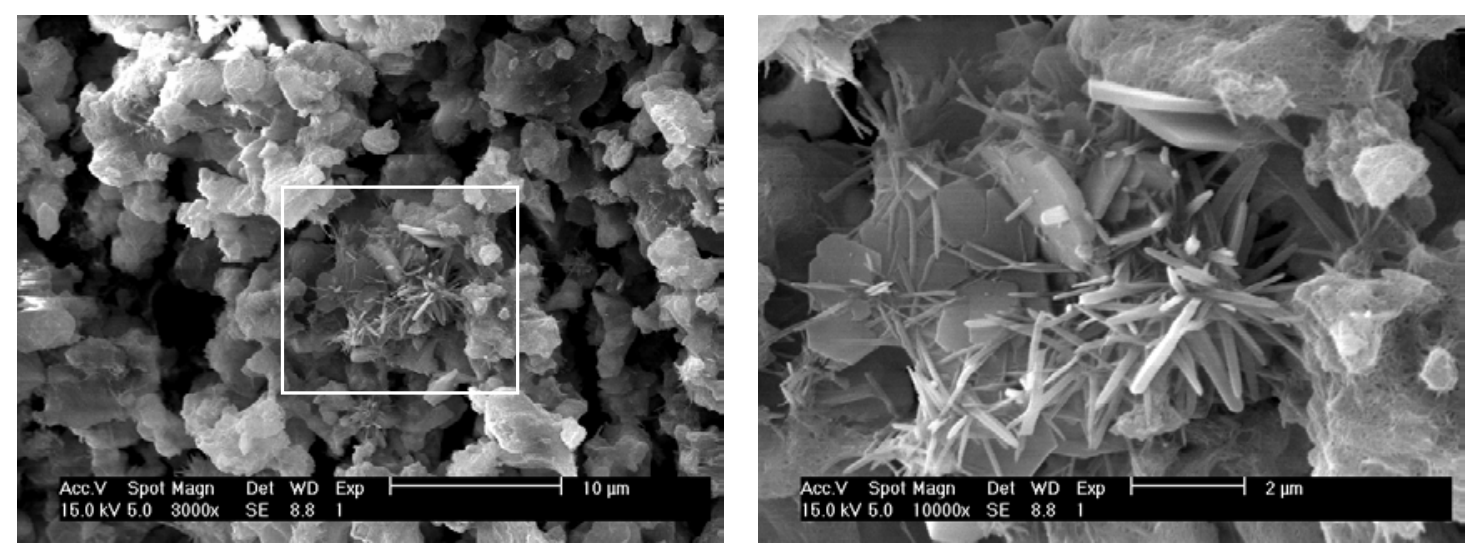

Figure 12. SEM micrographs of the matrix of RHA-C-L.5-1-4 mortar (after 120 days) containing hexagonal and needle-like crystals embedded within the carbonated phases.

\section{DISCUSSION}

Replacement of the cement by RHA and lime influenced the hardening mechanism, mechanical strength, porosity and microstructure of the mortars. Thermal analysis results indicated that while hardening of reference cement mortar was governed by the cement hydration, that of RHA-cement mortars occurred as a result of early-stage hydration combined with pozzolanic reaction and carbonation at later stage (Figure 8). Decrease in the calcium hydroxide content in the RHA-cement mortars upon hardening gives evidence to its consumption by carbonation and pozzolanic reaction. Carbonation is much more pronounced with the decrease in the cement content and increase in the porosity of the mortars. The reaction started to appear much more after 60 days for RHA-C.3-7 and after 28 days for RHA-C.5-5 and RHA-C.7-3. Pozzolanic reaction seems to start before 7 days and contributes to the formation of C-S-H phases upon hardening. The RHA-cement mortars achieved their ultimate strength at 7 days, confirming that early strength gain was mainly controlled by the rapid hydration of cement since pozzolanic reaction proceeds much slower [1-2]. Contribution of the pozzolanic reaction and carbonation to the strength development of these mortars is also evident as the strength values increased gradually until 180 days while no considerable increase was recorded in the strength of the reference cement mortar after 28 days (Figure 2 and Figure 3). All the RHA-cement mortars indicated a long-term strength development even though their strength values were lower than that of the reference cement mortar. Strength values became lower as cement was partially replaced by RHA respectively at $30 \%$-wt, $50 \%$-wt and 70\%-wt ratio. This was ascribed to their higher $\mathrm{W} / \mathrm{B}$ ratio than the reference cement mortar, which derived from high water demand of porous RHA particles having high specific surface area. This resulted in an increase in the porosity with the formation of large pores $(>0.1 \mu \mathrm{m})$ (Figure 6$)$. Increase in the volume of small pores $(<0.1 \mu \mathrm{m})$ was also observed due to the additional C-S-H phases formed by the pozzolanic reaction. This can be verified with SEM micrographs as the matrix of the RHA-cement mortars was mostly composed of well-connected flocs-like C-S-H phases with small pores in-between while that of the reference cement mortar was characterized by large pores containing needle-like and reticular C-S-H phases (Figure 9 and Figure 10).

RHA-cement-lime mortars had relatively lower compressive and flexural strength values than those of the RHA-cement mortars. Strength reduction was recorded at the very early stage of 28 days (Figure 4 and Figure 5). This reduction was also reported in the literature for the same type of mortar composition after 28 weeks [13] and for ternary grouts containing 
$10 \%$-wt cement after 60 days or more [14-15]. As the cement content was relatively low $(10 \%-w t)$, its hydration would be at the very early stage together with the pozzolanic reaction but carbonation would be expected to be much more effective at later stage. This could be verified with the thermal analysis results revealing that hydration and pozzolanic reaction were effective until 28 days when strength development was achieved. Carbonation started to be much more pronounced after 28 days when strength reduction was recorded. This could indicate that calcium carbonate phases formed afterwards could have a destructive effect on the initially hydrated cement phases. As pozzolanic reaction leading to additional C-S-H phases proceeds slowly, its contribution would be insufficient to the initially hydrated cement phases to overcome the effect of the calcium carbonate formation. In addition, partial carbonation of the C-S-H phases was also recorded by thermal analysis after 60 days with the slight decrease in the $\mathrm{C}-\mathrm{S}-\mathrm{H}$ phases and increase in the carbonated phases. The overall effect of this would be to weaken rather than to strengthen the existing C-S-H phases. This could also be the reason why RHA-cement-lime mortars exhibited a reduction in their early-stage strength. In agreement with the earlier research, it can be concluded that $10 \%$-wt cement was insufficient for the long-term strength development of these ternary blended mortars [14-15].

Carbonation depth of the blended cement mortars at any age was greater than that of the reference cement mortar. A correlation between carbonation depth and porosity of the mortars could be drawn since the carbonation depth increased with increasing porosity which contributes to the diffusion of the carbon dioxide into the core where calcium hydroxide is still present to carbonate [16]. Carbonation depth of the mortars is in agreement with the thermal analysis results revealing the calcium hydroxide content and carbonated phases.

Microstructural investigation by SEM revealed considerable differences among the reference cement mortar, RHA-cement and RHA-cement-lime mortars. While needle-like and reticular C-S-H phases were observed in the matrix of the reference cement mortar (Figure 9), flocs-like and fibrous-like C-S-H phases well connected to each other mostly composed the matrix of the RHA-cement mortars (Figure 10). Unreacted or partially reacted RHA grains could be detected in the matrix of the RHA-cement mortars even at the age of 120 days, indicating the ongoing pozzolanic reaction (Figure 11a-b). The mechanism of the pozzolanic reaction could be observed as well. The reaction started on the surface of the RHA grains, leading to the precipitation of C-S-H phases. When totally reacted, they became flocs-like $\mathrm{C}-\mathrm{S}-\mathrm{H}$ phases playing a bridging role between hydrated and unhydrated cement particles by growing from the grain surface towards the surrounding matrix (Figure 11c-d). This could help improving the microstructure of the interfacial transition zone between sand and the cement matrix. Different from the RHA-cement mortars, RHA-cement-lime mortars were characterized by rather poor microstructure composed of silica-rich carbonated phases that were agglomerated with rather large pores in-between. Clusters of hexagonal and needle-like crystals were embedded locally within the matrix. Lower strength values of these mortars could be related with their poor microstructure.

\section{CONCLUSIONS}

Hardening of cement in combination with RHA and lime occurred as a result of combined cement hydration, pozzolanic reaction and carbonation. Initial strength development of the RHA-cement mortars was mostly governed by the cement hydration while pozzolanic reaction contributed to the long-term strength development. Carbonation was favoured at the later stage with the increase in the porosity of the mortars due to high W/B ratio. High porosity led to relatively lower strength values when compared to the reference cement mortar. Compressive and flexural strength of each RHA-cement mortar increased gradually, 
indicating their long-term strength development. However, strength reduction was recorded at the very early stage of the mortars when cement in low content was used in combination with RHA and lime. This could be explained with the insufficient cement content, destructive effect of the calcium carbonate phases on the initially hydrated cement compounds and partial carbonation of the hydrated phases. The lowest cement content leading to long-term strength development for the ternary blended mortars will be further investigated.

\section{ACKNOWLEDGEMENT}

This study is the part of an ongoing Research Project (OT-project 3E030765) conducted at the Department and Master thesis research 'Performance Evaluation of Pozzolanic Rice Husk Ash Binder in Tanzania' by Jan Campforts at the K.U.Leuven. The research grant offered to Ozlem Cizer by the OT-project funded by K.U.Leuven is gratefully acknowledged.

\section{REFERENCES}

1. Massazza, F., Pozzolana and pozzolanic cements. In: Lea's Chemistry of Cement and Concrete, Hewlett P.C. ed., 4th Edn., Arnold, London, 1998, pp 471-631.

2. Taylor, H.F.W., Cement Chemistry. Academic Press Limited, London, 1990.

3. Ogawa K., Uchikawa H., Takemoto K., The mechanism of the hydration in the system $\mathrm{C}_{3}$ S-pozzolana. Cem. Concr. Res., 10, 1980, pp 683-696.

4. Wu Z.Q., Young J.F., The hydration of tricalcium silicate in the presence of colloidal silica. Journal of Materials Science, 19, 1984, pp 3477-3486.

5. Sharara, A., Didamony, H., Ebied, E., El-Aleem, A., Hydration characteristics of $\beta-C_{2} S$ in the presence of some pozzolanic materials. Cem. Concr. Res., 24, 1994, pp 966-974.

6. Collepardi M., Baldini G., Pauri M., Corradi M., Tricalcium aluminate hydration in the presence of lime, gypsum or sodium sulphate. Cem. Concr. Res., 8, 1978, pp 571-580.

7. Mehta P.K., Studies on blended Portland cements containing Santorin earth. Cem. Concr. Res., 11, 1981, pp 507-518.

8. Mehta, P.K. and Gjorv, O.E., Properties of Portland cement concrete containing fly ash and condensed silica fume. Cem. Concr. Res., 12, 1982, pp 587-595.

9. Chengzhi, Z., Aiqin, W., Mingshu, T., The filling role of pozzolanic material. Cem. Concr. Res., 26, 1996, pp 943-947.

10. Shinohara, Y., and Kohyama, N., Quantitative analysis of tridymite and cristobalite crystallized in rice husk ash by heating. Industrial Health, 42, 2004, pp 277-285.

11. EN 196-1, Methods of testing cement-Part 1: Determination of strength. European Standard, 1987.

12. EN 1936, Natural stone test method - Determination of real density and apparent density and of total porosity and open porosity. European Standard, 1999.

13. Stroeven, P., Bui, D. D., Sabuni, E., Ash of vegetable waste used for economic production of low to high strength hydraulic binders. Fuel, 78, 1999, pp 153-159.

14. Toumbakari E., Lime-Pozzolan-Cement grouts and their structural effects on composite masonry walls. Ph.D Dissertation, K.U.Leuven, Belgium, 2002.

15. Van Rickstal, F., Toumbakari, E., Ignoul, S., Van Gemert, D. Development of Mineral Grouts for Consolidation. In Consolidation of Masonry, Ed. D. Van Gemert, In: Advances in Materials Science and Restoration, no. 1. Freiburg: Aedification Publishers, 2003, pp 61-76.

16. Van Balen, K. and Van Gemert, D., Modeling Lime Mortar Carbonation. Materials and Structures, 27, 1994, pp 393-98. 